\title{
Decomposition of the Gender Wage Gap Using Matching: An Application for Switzerland
}

\author{
Dragana Djurdjevic* and Sergiy Radyakin*
}

JEL-Classification: C14, J16, J71

Keywords: discrimination, gender wage gap, matching

\section{Introduction}

In Switzerland, the issue of inequality between women and men has been of policy concern during the last decades. Both progress and stagnation are the special features in terms of gender equality over the period 1970-2000. Some progress has been done in the access to education (see OFS, 2003). Despite this gain, it is important to point out that some significant differences remain, especially in areas involving the repartition of domestic and work tasks. In Switzerland, the gender specialisation in different areas of life is a strong social norm (see OFS, 2003). Along with occupational segregation, this can be a source of wage inequalities between men and women. ${ }^{1}$ Our concern in this paper is to investigate one particular aspect of gender inequalities which is based on wage differentials between men and women.

In the international literature, a growing attention has been paid to this question of gender wage differentials (see BLAU and KAHN, 1997 and Altonji AND

* Dr. oec. HSG, Wüest \& Partner AG, Gotthardstrasse 6, CH-8002 Zürich, Switzerland; phone : ++41 (0) 442899166 ; fax : ++41 (0) 442899001 ; e-mail : djurdjevic@wuestundpartner.com; web page : www.wuestundpartner.com

** Master of Arts in Economics, Institut für Arbeitsökonomik, Wirtschaftswissenschaftliche Fakultät der Leibniz Universität Hannover, Königsworther Platz 1, D-30167 Hannover, Germany; phone : ++49 (0) 5117625620 ; fax : ++49 (0) 51176282 97, e-mail: Radyakin@aoek. uni-hannover.de; web page : www.wiwi.uni-hannover.de/aoek/personal/radyakin.htm

1 LaLive and STUtzer (2004) investigate the importance of social norms in explaining why women do not report a lower job satisfaction while persistent wage gaps are observed in Switzerland. In their study, wage differentials between men and women are attributed to the social norms about appropriate salaries for women. However, we can argue that these social norms can represent a form of barriers to the integration of women to the labour market. 
BLANK, 1999 for an overview). The way of addressing this issue has typically involved the distinction between the wage differences that can be due to different compositions of personal characteristics (such as age and education) and the wage differences that remain after controlling for these observed differences and that are commonly attributed to discrimination. ${ }^{2}$ To account for the "explained" and "unexplained" components of the wage gap, separate wage regressions are estimated for women and for men. This very popular method, called the BLINDER (1973) and OAXACA (1973) approach, thereafter BO has been widely criticised in the empirical literature because of its interpretation of the unexplained part of the wage gap as a result of discrimination. In fact, omission of observed variables, pre-labour market discrimination and endogeneity issues that can arise in the OLS estimation of the wage regression can make it difficult to distinguish between the different components of the wage gap and to assign the true part of the gap that is due to discrimination.

In addition, the $\mathrm{BO}$ approach presents other limitations. First, a particular relationship is assumed between the explained variables and the (log of) wages (with a potential risk of misspecification). Another, perhaps more important problem is the "support" problem in the distribution of the covariates. Men and women may not only differ in age, education and occupation..., but the distributions of these variables can overlap very little. This problem of lack of common support has been ignored in most studies on gender wage gaps. Typically, assumptions are made to extrapolate results: the behaviour of men is projected outside the observed range to form a comparison group for women having the same characteristics. This can lead to misleading results since individuals are compared though they are not comparable. For instance, in their study about the wealth gap between black and white households, BARSKY, Bound, CHARLES and LUPTON (2001) provide evidence that a large fraction of black households is not observed over a sizeable portion of the white earnings distribution. With the traditional $\mathrm{BO}$ decomposition that does not account for the differences in the supports of the distributions of the characteristics, Barsky, Bound, Charles and Lupton (2001) find that $20 \%$ of the average wealth gap is explained by earnings differences. On the contrary, this part amounts to $64 \%$ when comparable white/black households are used only. In his study about gender wage gap in Peru, Nopo (2004) reports similar empirical evidence about the importance of

2 A definition of wage discrimination that is commonly accepted and used in the literature suggests that discrimination against women arises when for seemingly equal work, women earn less than men (see Altonji and Blank, 1999). 
the common support problem in explaining the wage gap. An alternative to the common support problem consists in focussing on comparable individuals only, thus ignoring a lot of information which can be useful. In addition, the policy conclusions are made for the whole population while the analysis is made only for its part. The importance of the common support problem has been largely addressed in the evaluation literature (for a detailed discussion, see for instance LECHNER, 2001).

In this paper, we use a nonparametric technique which is based on matching. Matching methods have been widely used in the literature on evaluation in looking at the impact of a treatment on an outcome variable (see for instance Heckman, Lalonde and Smith, 1999). However, matching can be used in the analysis of gender wage differentials as well. In disentangling the explained and the unexplained components of these differentials, we have indeed to compute the counterfactual wage that women would receive if the distribution of their characteristics would be similar to that of men. In this paper, we use the matching procedure and the decomposition of the wage gap along the lines of Nopo (2004). The advantage of the exact matching procedure is that we can simultaneously estimate the common support and the mean counterfactual wage for the women on the common support. In addition, the decomposition of the wage gap explicitly accounts for differences in the supports of the distributions of characteristics.

However, the flexibility of this method is very costly: in the nonparametric setup, we face the problem of dimensionality which arises when we control for many covariates. The inclusion of many variables will indeed reduce the size of the cells and the number of matches. An alternative approach to exact (multivariate) matching would be propensity score matching which reduces a highdimensional estimation problem to a one-dimensional case (see RosEnBAum and Rubin, 1983). However, in terms of efficiency, it is not clear whether propensity score matching is superior to direct matching (see the efficiency issues discussed in details by Hahn, 1998; Heckman, Ichimura and Todd, 1998). As a consequence, we compare the results of the decomposition based on exact matching with the results of decompositions based on more commonly used propensity score matching algorithms.

Besides these methodological issues, taking account of gender differences in supports may also be important for policy implications. Gender differences in supports can indeed reflect a form of pre-labour market discrimination, because women face some "barriers to entry" in reaching certain individual characteristics that men achieve (see Nopo, 2004). Such barriers can for example be attributed to a different access to the education system, but also to the fact that working 
women still have to carry most of the burden for housework and childcare (see Altonji and Blank, 1999; WALdFogel, 1998). ${ }^{3}$ In the latter case, it will take a long time to reduce the gender wage gap, since it involves a change of social norms about men's and women's role on the labour market. As a consequence, measures facilitating the duality between work and family should prove to be useful in reducing gender wage differentials (see for instance BLAU and KAHN, 2000 for the US).

The paper is organised as follows. Section 2 presents some stylised facts about the measures aimed at promoting gender equality in Switzerland as well as an overview of the existing Swiss studies on the wage gender gap. In Section 3, data used for the empirical application are described and some descriptive statistics on gender wage differentials are reported. In Section 4, we present the econometrical model. Then, we discuss the results in Section 5. Section 6 concludes.

\section{Gender Equality in Switzerland}

\subsection{Institutional Framework}

In terms of national legislation in equal pay and equal opportunity, Switzerland is lagging behind the other OECD countries: the first federal law on equal wage and equal opportunity came into force only in July 1996. Concerning international legislation, Switzerland has ratified in 1997 the UN Convention on the Elimination of all forms of Discrimination Against Women. This ratification should help in promoting the equality between men and women in Switzerland. However, the federal structure of Switzerland implies that the Confederation is responsible for the application of international standards while cantons are the competent authorities which own their own political and juridical institutions. In this case, a lack of coordination between the different administrative levels can raise some issues of policy coherence in the application of the principle of equality between men and women.

3 Altonji and Blank (1999) point the importance of "pre-market human capital differences" such as differences in family expectations and in educational choices in explaining gender wage differences in the labour market. WALDFOGEL (1998) underlines the role of some institutional factors such as the lack of maternity leave in acting as structural barriers to the promotion of women with children in employment that is valuable in terms of work experience and thus in terms of higher pay. 


\subsection{Evolution in the Last 30 Years}

In order to evaluate the progress and the pitfalls established in the area of equality, regular detailed surveys by gender have been published by the Federal Statistical Office. These reports present some detailed indicators about gender equality in different areas such as education, working life and wages, social security and poverty as well as an overview of the situation in gender equality for the period from 1970 to 2000 . They show that gender differences with respect to education have narrowed in time. Since 1980, the share of individuals without post-obligatory schooling has reduced by $50 \%$ (see Appendix A.1). Nowadays, women are more likely to complete apprenticeship training than two decades ago. In addition, the proportion of women with a tertiary degree has more than doubled over this period. Similarly, female participation rates have continuously increased over the period 1970-2000. Despite this increase, the Swiss labour market remains still segmented. Indeed, full-time positions are primarily occupied by men while women are essentially working part-time (see Appendix A.1). Another indicator of equality is the proportion of men and women in different job positions. Between 1970 and 2000, the fraction of women having a supervisory function has continuously increased (see OFS report, 2005). This evolution is attributed to the progress in educational attendance of women. However, women remain still confined in female dominated sectors such as health care, clerical work and services (see Appendix A.1). The last, but not the least indicator of gender inequality concerns wage differentials. On average, women earn less than men. The gap amounts to $21 \%$ in the private sector and to $10 \%$ in the public sector. In both sectors, the gender wage gap has decreased between 1994 and 1998, but it has remained at its level thereafter (see Appendix A.2). If wage differentials exist for all economic sectors, these gaps vary a lot across the sector of activity. As a consequence, Switzerland has to pursue its efforts in encouraging more equality between men and women.

\subsection{Swiss Studies}

The issue of gender wage differences has been the focus of a number of studies in Switzerland. Since the seminal work by KugLER (1988), about ten studies have been published in this area. Table 1 gives an overview of these studies. It indicates that different estimation methods of wage equations and different data sets have been used. This leads not surprisingly to diverse results which do not help in the current public debate on gender wage differences (OFS, 2003). Most studies analysing the gender wage gap in Switzerland are based on parametric methods and use the BO decomposition for wages. 
Table 1: Overview of the Swiss Studies on the Gender Wage Gap

\begin{tabular}{|c|c|c|c|c|c|}
\hline Authors & Data & Period & Decomposition & $\begin{array}{c}\text { Wage gap } \\
\text { in } \%\end{array}$ & $\begin{array}{c}\text { Unexplained } \\
\text { component in \% }\end{array}$ \\
\hline Kugler (1988) & $\begin{array}{l}3 \text { datasets } \\
\text { merged }\end{array}$ & $1981-82$ & Oaxaca-Blinder & 43 & 7 \\
\hline $\begin{array}{l}\text { Brüderl, Diekmann } \\
\text { and Engelhardt (1993) }\end{array}$ & ISSP & 1987 & Oaxaca-Blinder & 81 & 38 \\
\hline $\begin{array}{l}\text { Diekmann } \\
\text { and Engelhardt (1995) }\end{array}$ & SLFS & 1991 & Oaxaca-Blinder & 43 & 16 \\
\hline Bonjour (1997) & SLFS & 1991-93 & Oaxaca-Blinder & 26 & {$[9-13]$} \\
\hline $\begin{array}{l}\text { Henneberger } \\
\text { and Sousa-Poza (1998) }\end{array}$ & SLFS & 1995 & Oaxaca-Blinder & 29 & {$[10-16]$} \\
\hline $\begin{array}{l}\text { Henneberger } \\
\text { and Sousa-Poza (1999) }\end{array}$ & SLFS & 1997 & Oaxaca-Blinder & 24 & {$[8-11]$} \\
\hline $\begin{array}{l}\text { Flückiger } \\
\text { and Ramirez (2000) }\end{array}$ & SWSS & $1994-96$ & Oaxaca-Blinder & 30 & 17 \\
\hline $\begin{array}{l}\text { Bonjour } \\
\text { and Gerfin (2001) }\end{array}$ & SLFS & $1991-95$ & $\begin{array}{l}\text { Oaxaca-Blinder } \\
\text { semiparametric* }^{*}\end{array}$ & $\begin{array}{l}21 \\
21\end{array}$ & $\begin{array}{r}10 \\
8\end{array}$ \\
\hline Sousa-Poza (2002) & SWSS & 1998 & Oaxaca-Blinder & [18-28] & [14-19] \\
\hline Sousa-Poza (2003) & SLFS & 1991-2001 & Oaxaca-Blinder & [23-23] & {$[10-18]$} \\
\hline
\end{tabular}

Notes: SLFS (Swiss Labour Force Survey); SWSS (Swiss Wage Structure Survey); ISSP (International Social Survey Programme); Kugler (Health Survey, Income and Health Survey, supplementary survey on labor supply);

* the numbers correspond to the $50 \%$ quantile of the wage distribution.

Kugler (1988) examines the gender wage gap for a sample of about 2500 individuals. Using the traditional BO decomposition, he finds that $93 \%$ of the gender wage gap of $43 \%$ can be accounted for. Using data from the 1987 International Social Survey Program, Brüderl, Diekmann and Engelhardt (1993) find a total wage gap of $81 \%$ and an unexplained wage gap of $38 \%$. A range of studies conduct the gender wage gap analysis using the data from the Swiss Labour Force Survey (SLFS). Depending on the estimation techniques and the variables used in these analyses, these studies find a gender wage gap of $20 \%-40 \%$ of which about $10 \%-20 \%$ cannot be explained by the specification used in these studies. We argue that these differences are due to differences in the specification of the wage equations. In addition, all these studies are based on the traditional $\mathrm{BO}$ decomposition that fails to recognise the problem of gender differences in the supports of the explanatory variables. Since gender occupational segregation 
is found to be important in the Swiss labour market (see OFS, 2003), assuming that all working women are comparable to working men will lead to misleading results.

Compared to the other Swiss studies, Bonjour and Gerfin (2001) use a distributional analysis to examine how the unexplained component of the wage gap varies over the wage distribution. Their main finding is that at the lower end of the wage distribution, a large part of wage difference is due to discrimination, whereas at the upper end of the wage distribution, most of the gender gap is explained by differences in human capital endowment. In their study, the BO decomposition is extended to explore the distribution of the unexplained wage differences. However, this strategy still ignores the problem of gender differences in the supports that we want to address in this paper. We suggest to investigate the gender wage gap using the matching method which has been proposed by Nopo (2004). To our knowledge, there is no empirical study for Switzerland that applies matching to investigate the gender wage gap.

\section{Data and Descriptive Statistics}

\subsection{Some Facts about Raw Gender Wage Gaps}

This section presents some descriptive statistics about the raw gender wage gap using the SLFS data that have been used in the empirical analysis. The general trend is that the raw gap has narrowed between 1996 and 2003: on average, women earn 32\% less than men in 1996 compared to $25 \%$ in 2003 (see Table 2). ${ }^{4}$ A further look at the different years seems to indicate that over the period 1996-2000, the raw gap decreases. From 2001, the raw wage gap remains relatively constant. Overall, for the period 1996-2003, men earn about 26\% (or 6.65 CHF) more than women.

\subsection{Description of the Variables Used}

This section presents the variables used in the empirical analysis. This study is based on the SLFS data collected by the Statistical Federal Office since 1991. The Survey is carried out once a year, during the 2nd quarter (April-June). It

4 The statistics presented in Table 2 are based on the selected samples used in the empirical analysis. The population in a particular year refers to the workers of that corresponding year satisfying the sample selection rules (see Section 3.2). 
Table 2: Absolute and Relative Raw Gender Wage Gap

\begin{tabular}{lcc}
\hline Year & in CHF & in \% \\
\hline 1996 & 7.43 & 31.7 \\
1997 & 5.83 & 24.2 \\
1998 & 6.79 & 28.7 \\
1999 & 6.57 & 27.1 \\
2000 & 5.72 & 22.4 \\
2001 & 6.40 & 24.6 \\
2002 & 7.04 & 27.5 \\
2003 & 6.62 & 25.0 \\
\hline
\end{tabular}

Notes: own computations from SLFS data; wages refer to hourly wages; the absolute wage gap is measured in current $\mathrm{CHF}$ and the relative wage gap in $\%$ of female wages.

covers the population of persons aged 15 or more who are permanent residents in Switzerland. The SLFS provides important internationally comparable information on the labour market situation in Switzerland. Questions are asked on work activity, professional experience, working times and conditions, job seeking, former occupation, reasons for not being economically active and incomes. The data collected provide information about socio-demographic characteristics of the employed, unemployed and inactive individuals.

This empirical study uses the waves from 1996 to 2003 . We choose to not use the first waves from 1991 to 1995 , because the sample size in each of these years was small making it insufficient for our matching procedure. Indeed, approximately 16,000 persons were interviewed each year. This sample size changes to about 40,000 persons from 2002 . That is why we prefer to focus on the second part of the decade.

The empirical analysis concentrates on workers who are not self-employed, not in the agricultural sector, not in a training programme (apprenticeship) or completing compulsory military service. We do not take people in agricultural sector, because their earnings are likely to be explained by random factors such as weather conditions. Similarly, we do not include self-employed, because it is difficult to distinguish between returns to human capital from returns to physical capital. In addition, we exclude students and employees older than 55, since they are also involved in the education and retirement decisions which are different from the employment decision. Finally, we drop all observations for which 
missing values are observed. ${ }^{5}$ Hourly wages are calculated using the yearly (net) labour income and the number of normal weekly working hours. ${ }^{6}$

Appendix A.3 presents the variables we use for the decomposition of gender wage gap. They include human capital characteristics such as age and education, personal characteristics such as marital status, household composition and foreign citizenship. We further control for job characteristics with variables capturing firm size, job position, industry sector and work experience. The choice of controlling variables does not follow strictly the human capital theory since we include demographic variables such as marital and family statuses. However, in their survey on race and gender differentials, Altonji and Blank (1999) provide evidence that differences in these latter variables are observed by gender for the US. Moreover, including controls for experience, job position and industry sector may be questionable to the extent they may be an outcome of discrimination. Despite this potential endogeneity problem, we believe that these variables have an important role in explaining the wages and cannot be ignored in our matching procedure. As a comparison with the other Swiss studies, Gerfin and Bonjour (2001) and SousAPozA (2003) also control for experience, tenure, firm size and occupation.

Table 3 presents some descriptive statistics for male and female employees. Men are over-represented among high educated workers. There are many more married men than married women (this is due to the sample selection of working women). This is also reflected in women's lower number of children. Women also have a lower level of work experience, are more likely to be employed in small firms and less likely to have a responsibility function. There is a strong occupational segregation: typically female occupations are clerical and services work, whereas men are more likely to work as operators, handworkers and assistants, but also in higher occupation such as managers and academicians. This occupational segregation is also reflected in women's higher propensity to work in the public sector. Turning to the evolution of personal and job characteristics in time, women are more similar to men in 2003 than in 1996: the share of women with a tertiary education increases from $25.34 \%$ in 1996 to $34.38 \%$ in 2003. Similarly, women are more likely to occupy a position with a responsibility function or a high qualified position such as manager in 2003 than in 1996. Finally, women are more likely to have a higher work experience in 2003 than in 1996.

5 In 2003, the final data set contains 20,838 individuals (9,958 women and 10,880 men).

6 The definition of hourly wages is restrictive, since we are implicitly assuming that individuals employed during the reference period are employed during the entire year. With the use of yearly labour income, it is thus not possible to identify persons who were without a job during a part of the year. This implies that hourly wages will be under-estimated. 
Table 3: Descriptive Statistics for 1996 and 2003

\begin{tabular}{|c|c|c|c|c|}
\hline \multirow{2}{*}{$\begin{array}{l}\text { Year } \\
\text { Variables }\end{array}$} & \multicolumn{2}{|c|}{1996} & \multicolumn{2}{|c|}{2003} \\
\hline & Women & Men & Women & Men \\
\hline CHF/hour & 23.46 & 30.88 & 26.52 & 33.14 \\
\hline Socio-demographics & & & & \\
\hline $\begin{array}{l}\text { Age } \\
15-24 \\
25-29 \\
30-34 \\
35-39 \\
40-44 \\
45-49 \\
50-55\end{array}$ & $\begin{array}{l}53.85 \\
43.14 \\
43.74 \\
41.05 \\
41.78 \\
46.53 \\
44.86\end{array}$ & $\begin{array}{l}46.15 \\
56.86 \\
56.26 \\
58.95 \\
58.22 \\
53.47 \\
55.14\end{array}$ & $\begin{array}{l}52.24 \\
50.32 \\
44.72 \\
45.94 \\
46.08 \\
45.93 \\
48.11\end{array}$ & $\begin{array}{l}47.76 \\
49.68 \\
55.28 \\
54.06 \\
53.92 \\
54.07 \\
51.89\end{array}$ \\
\hline $\begin{array}{l}\text { Marital status } \\
\text { single } \\
\text { married } \\
\text { divorced } \\
\text { widowed }\end{array}$ & $\begin{array}{l}46.40 \\
39.92 \\
68.95 \\
82.26\end{array}$ & $\begin{array}{l}53.60 \\
60.08 \\
31.05 \\
17.74\end{array}$ & $\begin{array}{l}47.42 \\
44.53 \\
62.60 \\
79.81\end{array}$ & $\begin{array}{l}52.58 \\
55.47 \\
37.40 \\
20.19\end{array}$ \\
\hline $\begin{array}{l}\text { Level of education } \\
\text { primary } \\
\text { secondary } \\
\text { tertiary }\end{array}$ & $\begin{array}{l}58.03 \\
48.34 \\
25.34\end{array}$ & $\begin{array}{l}41.97 \\
51.66 \\
74.66\end{array}$ & $\begin{array}{l}53.09 \\
52.11 \\
34.38\end{array}$ & $\begin{array}{l}46.91 \\
47.89 \\
65.62\end{array}$ \\
\hline $\begin{array}{l}\text { Foreign citizenship } \\
\text { Swiss } \\
\text { Foreign }\end{array}$ & $\begin{array}{l}46.42 \\
39.09\end{array}$ & $\begin{array}{l}53.58 \\
60.91\end{array}$ & $\begin{array}{l}49.46 \\
40.31\end{array}$ & $\begin{array}{l}50.54 \\
59.69\end{array}$ \\
\hline $\begin{array}{l}\text { Children } \\
\text { With children under } 15 \\
\text { Without children under } 15\end{array}$ & $\begin{array}{l}37.25 \\
48.74\end{array}$ & $\begin{array}{l}62.75 \\
51.26\end{array}$ & $\begin{array}{l}44.97 \\
48.68\end{array}$ & $\begin{array}{l}55.03 \\
51.32\end{array}$ \\
\hline Regional characteristics & & & & \\
\hline $\begin{array}{l}\text { Region of residence* } \\
\text { Deutschschweiz } \\
\text { Westschweiz }\end{array}$ & $\begin{array}{l}44.01 \\
46.45\end{array}$ & $\begin{array}{l}55.99 \\
53.55\end{array}$ & $\begin{array}{l}47.12 \\
47.96\end{array}$ & $\begin{array}{l}52.88 \\
52.04\end{array}$ \\
\hline Job characteristics & & & & \\
\hline $\begin{array}{l}\text { Firm size } \\
\text { less than } 20 \text { workers } \\
\text { between } 20 \text { and } 99 \text { workers } \\
\text { more than } 99 \text { workers }\end{array}$ & $\begin{array}{l}48.51 \\
38.14 \\
41.06\end{array}$ & $\begin{array}{l}51.49 \\
61.86 \\
58.94\end{array}$ & $\begin{array}{l}52.78 \\
43.47 \\
40.78\end{array}$ & $\begin{array}{l}47.22 \\
56.53 \\
59.22\end{array}$ \\
\hline $\begin{array}{l}\text { Responsibility function } \\
\text { without } \\
\text { with }\end{array}$ & $\begin{array}{l}53.52 \\
30.39\end{array}$ & $\begin{array}{l}46.48 \\
69.61\end{array}$ & $\begin{array}{l}56.58 \\
33.17\end{array}$ & $\begin{array}{l}43.42 \\
66.83\end{array}$ \\
\hline
\end{tabular}


Decomposition of the Gender Wage Gap Using Matching

\begin{tabular}{lcccc}
\hline Year & \multicolumn{2}{c}{1996} & & 2003 \\
Variables & Women & Men & Women & Men \\
\hline $\begin{array}{l}\text { Occupation } \\
\text { managers }\end{array}$ & 16.48 & 83.52 & 28.59 & 71.41 \\
academicians & 29.80 & 70.20 & 36.66 & 63.34 \\
technicians & 53.03 & 46.97 & 57.07 & 42.93 \\
clerical workers & 66.40 & 33.60 & 69.73 & 30.27 \\
services & 72.27 & 27.73 & 67.09 & 32.91 \\
operators & 59.26 & 40.74 & 60.63 & 39.37 \\
handworkers & 11.76 & 88.24 & 15.23 & 84.77 \\
assistants & 18.13 & 81.87 & 14.06 & 85.94 \\
Work type contract & & & & \\
non-permanent & 50.64 & 49.36 & 53.82 & 46.18 \\
permanent & 44.29 & 55.71 & 46.92 & 53.08 \\
Public sector & & & & \\
no & 39.09 & 60.91 & 40.28 & 59.72 \\
yes & 61.23 & 38.77 & 65.53 & 34.47 \\
Work experience & & & & \\
less than 6 months & 61.52 & 38.48 & 59.76 & 40.24 \\
between 6 and 24 months & 60.10 & 39.90 & 65.51 & 34.49 \\
between 2 and 5 years & 61.73 & 38.27 & 60.79 & 39.21 \\
more than 5 years & 40.23 & 59.77 & 43.19 & 56.81 \\
\hline Observations & 2,794 & 3,069 & 9,958 & 10,880 \\
\hline
\end{tabular}

Notes: own computations, results for the other years are presented in Appendix A.4

\section{Decomposition of the Gender Wage Gap Using Matching}

We begin this section with the description of the matching procedure which we use in the empirical analysis. In the second point, we address some issues related to our matching estimator: in particular, we discuss the limitations of our procedure and the potential biases of the resulting estimates.

\subsection{Description of the Matching Procedure}

This section draws on Nopo's study. Nopo (2004) develops a simple matching procedure to construct the counterfactual wage. Based on this procedure, Nopo suggests a new decomposition technique that accounts for gender differences in the distribution of individual characteristics. This approach is a fully nonparametric method, since one does no longer need to estimate a linear wage regression function. Second, the counterfactual mean wage is simulated only for 
the common support. This implies that no assumption on the out-of-support region is required. In order to construct the counterfactual wage, Nopo (2004) uses a matching procedure that selects two sub-samples of men and women who have the same characteristics.

Let $g^{m}(x)=E(W \mid X=x, m)$ denote the average wage for men with characteristics $x, F^{m}(x)$ the cumulative distribution function of individual characteristics $x$ among men and $S^{m}$ the support of the distribution of characteristics for men. Define $g^{f}\left(\right.$.), $F^{f}\left(\right.$.) and $S^{f}$ similarly for women. The key idea in Nopo's approach is that the supports of the distributions of characteristics for women and men might not completely overlap, so that decomposing the wage gap into two parts, the "endowment" and "remuneration" effects, has to be done for the common support only. For this purpose, let $S=S^{m} \cap S^{f}$ be the common support and

$$
p_{S \mid m}=p(X \in S \mid m)=\int_{S} d F^{m}(x)
$$

the probability measure of the set $S$ under the distribution $d F^{m}$ (.). Then, one can divide the male population into two subpopulations composed of individuals having characteristics that belong either to the common support $S$ or to the out of the common support $\bar{S}$ :

$$
E(W \mid m)=E_{S}(W \mid m) p_{S \mid m}+E_{\bar{S}}(W \mid m) p_{\bar{S} \mid m}
$$

Since $p_{\bar{S} \mid m}=p(X \in \bar{S} \mid m)=1-p_{S \mid m}$, we can rewrite equation (1) as following:

$$
E(W \mid m)=p_{\bar{S} \mid m}\left[E_{\bar{S}}(W \mid m)-E_{S}(W \mid m)\right]+E_{S}(W \mid m)
$$

Similar computations can be done for women and we get the following expression:

$$
E(W \mid f)=p_{\bar{S} \mid f}\left[E_{\bar{S}}(W \mid f)-E_{S}(W \mid f)\right]+E_{S}(W \mid f)
$$

Equations (1') and (2) permit to write the total gender wage gap $\Delta$ :

$$
\Delta \equiv E(W \mid m)-E(W \mid f)
$$




$$
\begin{aligned}
\Delta= & \underbrace{\left[E_{S}(W \mid m)-E_{S}(W \mid f)\right]}_{I}+\underbrace{p_{\bar{S} \mid m}\left[E_{\bar{S}}(W \mid m)-E_{S}(W \mid m)\right]}_{I I} \\
& +\underbrace{p_{\bar{S} \mid f}\left[E_{\bar{S}}(W \mid f)-E_{S}(W \mid f)\right]}_{I I I}
\end{aligned}
$$

Part I of this expression involves the differences of wages between men and women over the common support only, while part II (resp. III) concerns wage differences between men (resp. women) in and out-of-the support.

Finally, part I in equation (3) can be decomposed as in BO decomposition by adding and subtracting the counterfactual mean wage

$$
\int_{S} g^{m}(x) d F_{S}^{f}(x)
$$

with $d F_{S}^{f}(x)$ being the density of characteristics in the subpopulation of women belonging to the common support. ${ }^{7}$ The counterfactual wage represents the average wage of women they would get if they were paid as men possessing the same characteristics. We obtain the following expression:

$$
\begin{aligned}
E_{S}(W \mid m)-E_{S}(W \mid f) \equiv & \int_{S} g^{m}(x) d F_{S}^{m}(x)-\int_{S} g^{f}(x) d F_{S}^{f}(x) \\
E_{S}(W \mid m)-E_{S}(W \mid f)= & \int_{S} g^{m}(x)\left[d F_{S}^{m}(x)-d F_{S}^{f}(x)\right] \\
& +\int_{S}\left[g^{m}(x)-g^{f}(x)\right] d F_{S}^{f}(x)
\end{aligned}
$$

As in $\mathrm{BO}$ decomposition, the first and the second parts of equation (4) represent the "explained" and the "unexplained" parts of the wage gap, but now on the common support only. As a consequence, the Nopo's decomposition involves 4 components:

$$
\Delta=\Delta_{m}+\Delta_{x}+\Delta_{o}+\Delta_{f}
$$

with

$$
\begin{aligned}
& \Delta_{m}=p_{\bar{S} \mid m}\left[E_{\bar{S}}(W \mid m)-E_{S}(W \mid m)\right], \\
& \Delta_{x}=\int_{S} g^{m}(x)\left[d F_{S}^{m}(x)-d F_{S}^{f}(x)\right],
\end{aligned}
$$

$7 d F_{S}^{f}(x)=d F^{f}(x) / P_{S \mid m}$ is scaled such that the integral integrates to one. 


$$
\begin{aligned}
& \Delta_{o}=\int_{S}\left[g^{m}(x)-g^{f}(x)\right] d F_{S}^{f}(x) \text { and } \\
& \Delta_{f}=p_{\bar{S} \mid f}\left[E_{\bar{S}}(W \mid f)-E_{S}(W \mid f)\right],,
\end{aligned}
$$

where $p_{\bar{S} \mid m}$ (resp. $p_{\bar{S} \mid f}$ ) are estimated by the empirical probabilities of being unmatched conditional on being a man (resp. a woman).

The component $\Delta_{m}$ stands for the part of the gap that can be explained by differences between men in and men out of the common support, i.e. between those men whose characteristics can be matched to women's characteristics and those who remain unmatched. For instance, it is possible to observe men of 35 years old with a university degree who have been working for more than 8 years at managerial occupations, but it is not possible to find women with a similar combination of characteristics. This component sheds some light on wage differences that can be attributed to the fact that some characteristics that men typically own are not observed among women and these characteristics are highly rewarded (if this component is positive) in the labour market. The component $\Delta_{f}$ has a similar interpretation between matched and unmatched women. For this component, we cannot find men who have the same characteristics as women. For instance, it is possible to observe Swiss married women of 45 years old with obligatory schooling and with 2-3 years of work experience, while we cannot find similar men.

As previously mentioned the components $\Delta_{x}$ and $\Delta_{o}$ represent the "endowment" and "remuneration" effects of the gap as in BO decomposition. The component $\Delta_{x}$ represents the part of the wage gap that can be explained by differences in the distribution of human capital variables between men and women (but over the common support). For example, it is possible to observe both men and women with a university degree, but men are more represented in this category than women. As a consequence, $\Delta_{x}$ represents the decrease in the wage gap should the distribution of female characteristics become the same as the distribution of male characteristics over the common support. Lastly, the component $\Delta_{o}$ captures the residual part of the wage gap. The methodological issues that arise in the matching procedure have a direct impact on the interpretation of $\Delta_{o}$. That is why we discuss this component in more details in Section 4.2.

Nopo (2004) proposes a matching procedure in order to estimate the counterfactual wage and the four components of the decomposition. In this procedure, gender is considered to be the treatment variable. The counterfactual wage for women stands for the wage women would earn, had they been men. ${ }^{8}$ It is estimated

8 To build this counterfactual, we take women without replacement and men with replacement. As an alternative, we can take men without replacement and women with replacement in order 
by averaging the observed wage of the men with the same characteristics. This is done under the assumption that the observed characteristics explain the productivity and earnings of individuals. Assumptions underlying the matching procedure are discussed further in Section 4.2. Table 4 presents the matching algorithm.

Table 4: Matching Algorithm for the Estimation of the Four Components

\begin{tabular}{ll}
\hline Step1 & For each woman in the sample, do steps 2 and 3. \\
Step2 & $\begin{array}{l}\text { Select all observations from the sub-sample of men who have the same charac- } \\
\text { teristics as the woman of step } 1 \text {. Do not remove these selected observations such } \\
\text { that they can be used again. Denote these men as matched. If no observations are } \\
\text { selected in this step, denote the woman chosen in step } 1 \text { as unmatched, otherwise as } \\
\text { matched. }\end{array}$ \\
Step3 & $\begin{array}{l}\text { Compute the counterfactual wage of the woman selected in step } 1 \text { as the weighted } \\
\text { average wage of the men selected in step } 2 .\end{array}$ \\
Step4 & $\begin{array}{l}\text { Compute } \Delta_{m}, \Delta_{x}, \Delta_{o} \text { and } \Delta_{f} \text { using the actual wage variable, the new synthetic wage } \\
\text { variable and the "match" dummy variable (which is coded by } 1 \text { whenever a woman } \\
\text { (resp. a man) is matched to a man (resp. a woman)). }\end{array}$ \\
\hline
\end{tabular}

Notes: matching is done with replacement (the same man can be used more than once in forming the control group); exact matches are used (see Abadie and Imbens, 2004 for a detailed survey about the different matching methods for the estimation of treatment effects).?

to simulate the male wages men would earn, had they been women. This is similar to the male and female $\mathrm{BO}$ wage decompositions. We did the estimation with these two definitions of the counterfactual and we get the same qualitative results.

9 To impute the counterfactual outcomes, matching estimators use outcomes of the nearest neighbours. Given a metric such as Euclidian or Mahalanobis distance and given the fact that matching is with or without replacement, the objective is to choose the number of matches needed to form the control group. In case of matching without replacement, matched pairs are formed and the average treatment effect on the treated is obtained by averaging differences in outcomes within the pairs. In case of matching with replacement, ABADIE and IMBENS (2004) implement a matching estimator where a treated observation is matched with a fixed number of control observations (the first $M$ nearest neighbours). In this framework, they show that the matching estimator is subject to a bias, because matching is not exact. The order of the bias is given by the dimension of the continuous variables which are used for the matching procedure. Abadie and Imbens (2004) provide an estimator that removes this bias and which is $\sqrt{N}$ consistent and asymptotically normal. This estimator is implemented as an ado file in Stata (see Abadie, Drukker, Herr and Imbens, 2003). 


\subsection{Methodological Issues to Our Matching Estimator}

The aim of our study is to account for the differences in earnings by gender when the distribution of the characteristics of men and women do not overlap completely, thus when the common support has to be enforced. Our focus is a descriptive one: we establish the main features of the four components-decomposition and stress the importance of the common support condition. In assessing a gender wage gap adjusted for men's and women's characteristics, other important issues do arise, of course. When the working sample of women and men do not form a random subgroup of the labour market, selectivity in participation has to be considered. Another prominent issue concerns the potential endogeneity of several of the variables which are typically included in the wage equation. Unobserved heterogeneity also deserved to be mentioned.

\section{Problem of Sample Selection}

An important methodological issue concerns sample selection due to participation decisions of women and the fact that these decisions can influence wages. ${ }^{10}$ To treat the selectivity problem, two technical problems have first to be solved:

i) the availability of good instruments which are difficult to find in practice and

ii) the inclusion of counterfactual wages for women who had not participated have they participated in our 4-components wage decomposition.

These questions deserve a new paper. Since our study is mainly descriptive, we leave the treatment of self-selection for further research. ${ }^{11}$

10 There is evidence by Mulligan and Rubinstein (2005) and Olivetti and Petrongolo (2006) that most of the current discrimination can be attributed to changes in participation decisions of women. Weichselbaumer and Winter-Ebmer (2005) review the empirical literature on gender wage differentials and find that better labour market endowments of women is the main reason explaining why the raw gap has reduced over time.

11 In the literature, it is common to correct the selectivity bias by applying a sample selection model which takes the participation decision of women into account. After using the Heckman's two-stage procedure, "potential" wages of actually non-working women can be imputed from those women who are actually working. In order to be valid, the Heckman correction technique requires the availability of instruments that are related to the propensity to work but not to wages. Since, in practice such exclusion restrictions are hard to find, this highlights the potential weakness of the Heckman approach. 


\section{Problem of Endogeneity}

Just as in the standard two components-decomposition, we encounter the problem of potential endogeneity in some variables. Occupation and job position may already be the result of discrimination. In the literature, it has been often referred to pre-labour market discrimination, The consequence is that the "unexplained" part of the gap which is often interpreted as an estimate of wage discrimination will underestimate the true effect of current discrimination. On the other hand, the residual part may still consist of unobserved differences in human capital characteristics, thus overstimating the true effect of discrimination. Due to these ambiguities, we will not do any interpretation of $\Delta_{o}$ in terms of discrimination. As a consequence, our non-parametric approach does not solve the problem of choice of variables, although it eliminates the problem of specification of earnings.

\section{Estimation Results}

\subsection{Differences in the In and Out of the Common Support Samples}

In this section, we look more precisely at the samples of matched and unmatched individuals. ${ }^{12,13}$ Table 5 shows how the differences between them in terms of some characteristics have behaved in time. For example, among matched individuals, the share of individuals with a tertiary education increases steadily in time: it has more than doubled from $11.8 \%$ in 1996 to $25.3 \%$ in 2003 . On the contrary, the proportion of high educated individuals remains relatively stable in the unmatched sample. We find similar evidence for the share of individuals with a supervisory function from the year 1997. An additional proof is provided by the share of managers and academicians. In the matched sample, the fraction of managers increases steadily from $1.6 \%$ in 1996 to $5.2 \%$ in 2003 while it has slightly increased among unmatched individuals. This is also confirmed by the fraction of academicians which has almost doubled over the observation period

12 The software package Stata 8.0 was used to obtain all estimates in the paper. The sub-sampling results were obtained using TurboMatch 1.0 - a computer program specifically developed to perform the decomposition described in this paper. This program shows better performance as compared to a similar Stata routine and works under Microsoft Windows operating system. ("Microsoft Windows" is a registered trademark of Microsoft Corp.) More information is available from the authors upon request.

13 It is worth noting that the percentage of matches is between $20 \%$ and $40 \%$ and is higher for the years 2002 and 2003 which provide larger samples. This is explained by the fact that it is easier to find an exact match in larger samples. 
Table 5: Distribution of Some Characteristics in the In and Out the Common Support Populations

\begin{tabular}{l|rr|rr|rr|rr}
\hline \multirow{2}{*}{ Year } & \multicolumn{2}{|c|}{1996} & \multicolumn{2}{c|}{1997} & \multicolumn{2}{c}{1998} & \multicolumn{2}{c}{1999} \\
Sample & \multicolumn{1}{|c|}{ In } & Out & \multicolumn{1}{c|}{ In } & Out & In & Out & \multicolumn{1}{c}{ In } & Out \\
\hline less than 30 years old & 34.3 & 24.4 & 38.0 & 24.2 & 32.8 & 24.1 & 28.6 & 24.1 \\
between 30 and 40 years old & 31.6 & 33.1 & 30.8 & 33.2 & 32.0 & 34.3 & 35.6 & 34.1 \\
between 40 and 50 years old & 20.8 & 28.6 & 19.0 & 28.7 & 22.2 & 28.8 & 22.0 & 29.4 \\
more than 50 years old & 13.3 & 13.9 & 12.2 & 14.0 & 13.0 & 12.8 & 13.9 & 12.4 \\
married & 47.6 & 59.8 & 44.0 & 58.7 & 46.2 & 57.5 & 46.8 & 57.7 \\
tertiary level of education & 11.8 & 25.3 & 12.8 & 25.3 & 15.1 & 26.4 & 15.0 & 26.7 \\
with children under 15 & 24.9 & 38.2 & 23.9 & 37.5 & 24.8 & 37.2 & 25.1 & 37.9 \\
with responsibility function & 33.9 & 39.4 & 30.6 & 41.1 & 37.5 & 41.0 & 40.5 & 41.2 \\
managers & 1.6 & 6.3 & 2.6 & 5.9 & 2.9 & 7.2 & 4.5 & 6.3 \\
academicians & 11.8 & 15.8 & 11.9 & 15.9 & 13.0 & 16.5 & 12.6 & 17.5 \\
clerical workers & 27.6 & 14.0 & 26.7 & 13.5 & 23.8 & 14.2 & 23.0 & 13.8 \\
services & 11.0 & 14.2 & 11.9 & 14.9 & 13.1 & 14.1 & 11.0 & 14.2 \\
more than 5 years of experience & 88.5 & 70.8 & 87.1 & 74.8 & 86.9 & 75.6 & 88.9 & 74.2 \\
\hline
\end{tabular}

\begin{tabular}{l|rr|rr|rr|rr}
\hline \multirow{2}{*}{$\begin{array}{l}\text { Year } \\
\text { Sample }\end{array}$} & \multicolumn{2}{|c|}{2000} & \multicolumn{2}{c|}{2001} & \multicolumn{2}{c}{2002} & \multicolumn{2}{c}{2003} \\
\hline less than 30 years old & \multicolumn{1}{c|}{ In } & Out & \multicolumn{1}{c}{ In } & Out & In & Out & \multicolumn{1}{c}{ In } & Out \\
between 30 and 40 years old & 28.8 & 22.8 & 23.6 & 22.8 & 25.3 & 24.5 & 23.4 & 25.0 \\
between 40 and 50 years old & 35.4 & 33.5 & 41.6 & 33.4 & 33.5 & 32.2 & 34.3 & 31.5 \\
more than 50 years old & 21.7 & 30.4 & 21.8 & 30.0 & 24.9 & 30.3 & 27.0 & 30.0 \\
married & 13.1 & 13.2 & 12.9 & 13.8 & 16.3 & 13.0 & 15.4 & 13.4 \\
tertiary level of education & 46.4 & 56.9 & 52.9 & 56.3 & 52.2 & 56.3 & 54.1 & 54.3 \\
with children under 15 & 19.5 & 26.0 & 22.4 & 27.0 & 22.8 & 26.7 & 25.3 & 29.0 \\
with responsibility function & 25.4 & 38.1 & 31.6 & 38.0 & 29.6 & 39.1 & 31.3 & 38.2 \\
managers & 38.2 & 40.5 & 34.7 & 40.5 & 39.2 & 39.3 & 36.7 & 41.9 \\
academicians & 4.5 & 6.2 & 3.6 & 5.8 & 4.5 & 7.0 & 5.2 & 7.4 \\
clerical workers & 17.9 & 16.3 & 19.2 & 16.8 & 20.1 & 15.2 & 20.2 & 16.5 \\
services & 17.9 & 14.6 & 19.1 & 13.8 & 17.0 & 13.9 & 16.7 & 13.8 \\
more than 5 years of experience & 87.3 & 75.5 & 88.1 & 75.4 & 89.7 & 71.5 & 88.5 & 70.8 \\
\hline
\end{tabular}

Notes: own computations. 
in the matched sample. Note that from 2000, the share of academicians among matched individuals exceeds the one for the unmatched individuals.

As a conclusion, the difference between matched and unmatched samples in terms of high education and high job position has reduced over time. This is in line with the findings from the OFS report (2003) that women have begun to penetrate traditionally male dominated areas. However, the concentration of women in these areas is still lower than that of men as it is indicated by the higher share of individuals with a good education and a good position in the unmatched sample than in the matched sample.

\subsection{Evolution in Time}

Using the variables reported in Table 3, we apply the exact matching procedure to estimate the gender wage differential in Switzerland for each year of the period 1996-2003. Figure 1 shows the dynamics of the four components of the wage gap obtained after matching together with the $95 \%$ confidence area (shadowed area). ${ }^{14}$

The first graph refers to $\Delta_{f}$ the part of the wage gap that would have disappeared if the unmatched women had on average the same wages as their matched counterparts. We observe that the variation of this component is rather small over the period of study and it stays in the vicinity of 1 CHF. In addition, $\Delta_{f}$ is statistically significant in almost all years (the exception is for 1997). This suggests that ignoring the problem of differences in gender supports like it is done in some evaluation studies can result in biases since incomparable individuals are compared. In addition, restricting the analysis to the common support only can lead to results that are not applicable to the whole population.

More intriguing evidence comes from the second graph which refers to $\Delta_{m}$, the part of the wage gap that would have disappeared if the unmatched men had on average the same wages as the matched men. This part steadily declines over the period of study. This indicates that more and more women obtain combinations of characteristics that were exclusively men's before. Hence, the differences between the matched and unmatched men reduce in time and move to zero from the year 2002 . The $\Delta_{m}$ component could be a crude measure of the female disadvantage in access to particular combinations of characteristics, which are rewarded on the market. We also find some support for this scenario from

14 As expected, the confidence intervals are much narrower in the years 2002 and 2003 due to the significantly larger amount of observations present in the dataset for these years. More details on the construction of the confidence intervals are available in the discussion paper. 
Figure 1: Confidence Intervals of the Four Components of the Wage Gap
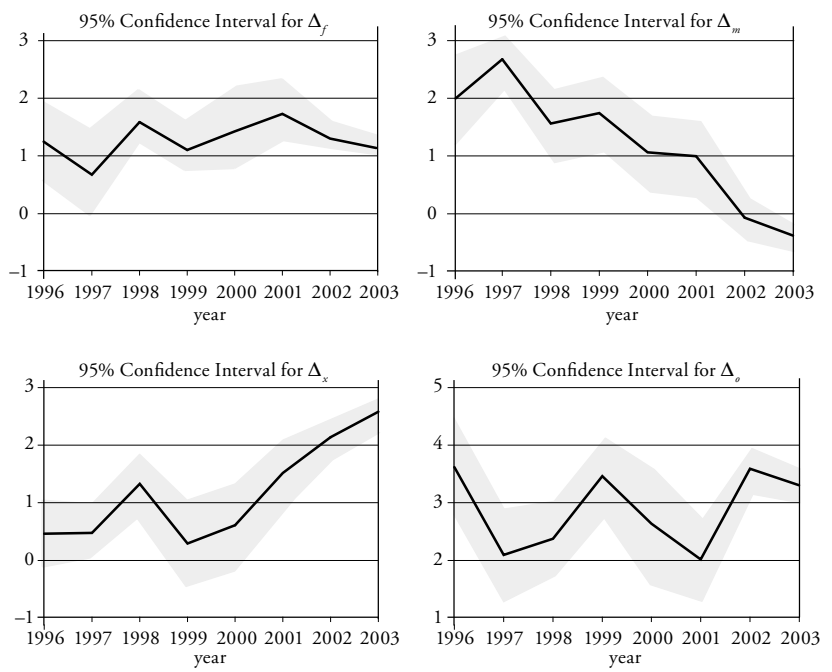

Notes: own computations.

Table 3. Over time, the distribution of characteristics of women shifts towards that of men (there are more and more women with higher levels of education, occupying high qualified job positions such as managers, etc.) This increases the chances of women for having the same characteristics as men. Hence, it is less likely to observe significant differences between matched and unmatched men. Figure 1 provides further support to the latter scenario. Indeed, the third graph represents, $\Delta_{x}$, the component of the wage gap that would have disappeared if the distribution of women's characteristics on the common support was the same as the distribution of men's characteristics on the common support. Figure 1 indicates that this component is steadily growing since 1999 . This pattern can be interpreted by the fact that although women succeed in entering traditionally males' domains, their concentrations in these areas still differ from men's concentrations. Together with $\Delta_{m}$ and $\Delta_{f}$, this component stands for the explained part of the wage gap. Since $\Delta_{x}$ is higher than $\Delta_{m}$ and $\Delta_{f}$, we can conclude that the differences in human 
capital matter more in explaining the gender wage gap than the differences in the gender supports, although these latter differences are significant.

Finally the fourth graph in Figure 1 shows the dynamics of the unexplained component of the wage gap $\Delta_{o}$. It is statistically significant in all years of study. However, no systematic pattern is observed. Instead, $\Delta_{o}$ fluctuates around about 3 CHF. Such volatility in $\Delta_{o}$ raises some doubts about the fact that it can be attributed solely to discrimination. Indeed, if it would be the case, $\Delta_{o}$ would reflect the change in the employers' behaviour (employers' valuation of female workers as compared to male workers), hence it should change only gradually.

As a comparison with the other Swiss studies, we find for the period 1996-2001 an average unexplained component of $10 \%$ for an average wage gap of $23 \%$. This means that $57 \%$ of the wage gap is explained. In the study by SousA-Poza (2003), $46 \%$ of the raw gap is explained for this period while a share of $62 \%$ of the wage gap is explained in the study by Gerfin and Bonjour (2001).

\subsection{Matching vs. BO Decomposition}

In this section, we are interested in how the results from matching decomposition do differ from those obtained after BO decomposition. As previously mentioned, the main issue with $\mathrm{BO}$ decomposition consists in ignoring the gender differences that can arise in the supports. As a consequence, if the linear specification of the wage regression on the common support is correct, then we should have similar results to those obtained after matching. ${ }^{15}$ Figure 2 compares the mean effects for the unexplained and explained components of the gap obtained after applying BO without restricting to the common support (called thereafter "unrestricted BO"), BO with restricting to the common support ("restricted BO") and matching. The left (resp. right) graph represents the results for the unexplained (resp. explained) component of the gap. In both graphs, we plot the confidence intervals for the parameters obtained using unrestricted BO. First, Figure 2 provides some evidence on our expectation that restricting the analysis on the common support will make the results of BO closer to those after matching. Indeed, in both graphs, the solid and broken lines are close one to each other. In addition, the right graph sheds some light on the importance of the gender differences in the supports. Both explained components gap obtained using restricted $\mathrm{BO}$ and using matching do not belong to the confidence interval obtained using unrestricted BO. As a consequence, differences in supports account for a significant share of

15 Note that in the linear specification, we use the same variables as in the matching procedure. In addition, we use exclusively dummies for all the covariates. For instance, age is not left as a continuous variable. 
the wage gap. This result is also illustrated in the top graph of Figure 2. Depending on the year of study, it seems that restriction to common support in BO leads to an over or under-estimation of the unexplained component of the gap while the extrapolation assumption (ignorance of the common support) always leads to the overestimation of the explained part of the wage gap. Finally, the similarity of the results between the restricted $\mathrm{BO}$ and the matching decompositions indicates that the $\mathrm{BO}$ decomposition still provides good results when it is applied on the common support and when the linear regression is correctly specified. ${ }^{16}$

\subsection{Comparison with Propensity Score Matching}

In our matching procedure of Table 4, the conditioning variables are all discrete and we are using exact matches: a woman is matched whenever we find an identical man in terms of $X$. As argued by FröLICH (2003), the exact matching procedure is very conservative, restrictive and is likely to lead to a non-compact common support, where a "36-year old woman and a 38-year old woman are matched while a 37-year old woman is not". In addition, FröLICH (2003) shows in a small Monte Carlo analysis that exact matching performs worse than propensity score matching. Since exact matching is not often used in the empirical literature, we compare it with the calliper matching (also known as radius matching) which is one of the other more commonly used matching algorithms.

Propensity score is estimated using binomial probit model. In the estimation of the propensity score we use the same explanatory variables as in our exact matching procedure. Table 6 reports the sample sizes for women and men and the raw wage gap followed by decompositions based on exact matching (Panel I) and calliper matching (Panel II). While in exact matching we are guaranteed to compare similar (comparable) individuals this is not true for the calliper matching algorithm. ${ }^{17}$ To avoid the presence of outliers, i.e. of individuals which have very

16 Note that the distances between the restricted $\mathrm{BO}$ and the matching decompositions are due to the parametric specification of wage functions in BO decomposition. The effect of applying parametric restrictions is much less important in the restricted $\mathrm{BO}$ decomposition than in the unrestricted one.

17 The balancing property of propensity score is crucial in the matching procedure based on the propensity score. By definition, exact matching on $X$ guarantees that the comparison group is similar to the treated group. When using propensity score matching with the propensity score function being preliminarily estimated, we have to check that the matches obtained afterthe algorithm are of good quality. In our paper, we apply the test procedure implemented by LEUVEN and SIANESI (2003) for Stata 8.0 in order to test the balancing property in the calliper and nearest neighbour matching procedures. 
Figure 2: Comparing BO and Matching Decompositions

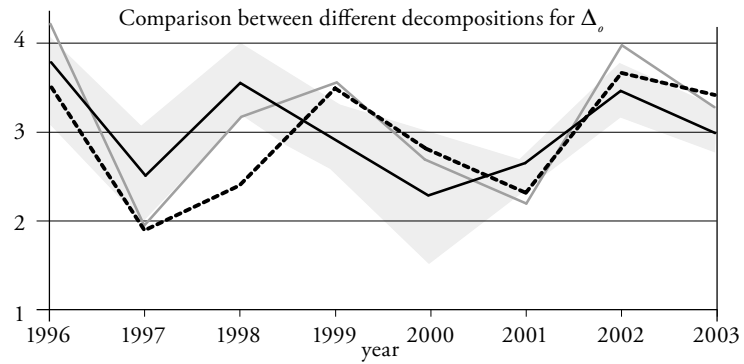

Comparison between different decompositions for $\Delta_{x}$

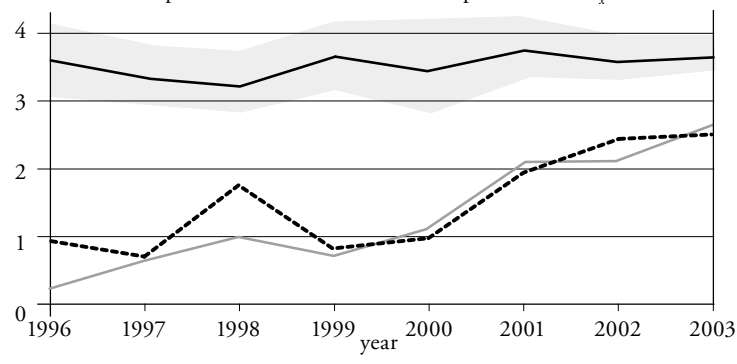

--- matching — restricted BO - unrestricted BO

Notes: own computations.

rare combinations of characteristics and thus positioned remotely on the propensity score scale, we choose to first run a nearest-neighbour matching and then to compute the distances between the matches (see for instance LeCHNER, MiqueL and Wunsch, 2004) until all our matched samples become balanced. ${ }^{18}$

18 The final calliper parameter is set to 0.00001 . To assess the quality of matches, we also tried different calliper parameters. These results are not presented in Table 6 but are available from the authors upon request. Additional results about the "classical" nearest-neighbourhood matching algorithm can be downlodable from the discussion paper under the following URL link: http://www.bwl.tu-darmstadt.de/vwl/forsch/veroeff/papers/ddpie_155.pdf. 
Table 6: Decompositions Based on Exact and Calliper Matching

\begin{tabular}{lcccccccc}
\hline & 1996 & 1997 & 1998 & 1999 & 2000 & 2001 & 2002 & 2003 \\
\hline Total women & 2,794 & 2,828 & 2,882 & 3,243 & 3,235 & 3,423 & 7,134 & 9,958 \\
Total men & 3,069 & 3,107 & 3,169 & 3,439 & 3,311 & 3,381 & 6,958 & 10,880 \\
Raw gap & 7.43 & 5.83 & 6.79 & 6.57 & 5.72 & 6.40 & 7.04 & 6.62 \\
\hline Panel I: Exact matching & & & & & & & \\
$\Delta_{o}$ & 3.55 & 1.89 & 2.40 & 3.49 & 2.78 & 2.30 & 3.66 & 3.42 \\
$\Delta_{x}$ & 0.92 & 0.69 & 1.76 & 0.81 & 0.98 & 1.94 & 2.42 & 2.50 \\
$\Delta_{m}$ & 1.63 & 2.22 & 1.05 & 1.24 & 0.88 & 0.45 & -0.38 & -0.39 \\
$\Delta_{f}$ & 1.33 & 1.04 & 1.58 & 1.03 & 1.07 & 1.71 & 1.34 & 1.09 \\
matched women & 697 & 753 & 772 & 895 & 877 & 934 & 2,629 & 3,799 \\
matched men & 665 & 720 & 710 & 850 & 838 & 885 & 2,581 & 4,155 \\
\hline Panel II: Calliper matching & & & & & & & \\
$\Delta_{o}$ & 3.37 & 1.88 & 2.40 & 3.19 & 2.65 & 2.58 & 3.99 & 3.27 \\
$\Delta_{x}$ & 0.67 & 0.50 & 1.68 & 0.94 & 0.88 & 1.73 & 2.10 & 2.35 \\
$\Delta_{m}$ & 1.73 & 2.40 & 1.11 & 1.37 & 1.12 & 0.57 & -0.39 & 0.06 \\
$\Delta_{f}$ & 1.66 & 1.05 & 1.60 & 1.06 & 1.07 & 1.53 & 1.33 & 0.94 \\
matched women & 759 & 819 & 843 & 977 & 949 & 1,029 & 2,890 & 4,421 \\
matched men & 730 & 801 & 768 & 923 & 920 & 983 & 2,868 & 4,821 \\
\hline epsilon (× 0.0001) & 0.1 & 0.1 & 0.1 & 0.1 & 0.1 & 0.1 & 0.1 & 0.1 \\
\hline
\end{tabular}

Notes: The components of the decompositions are in current CHF for the corresponding years, in the calliper matching "epsilon" is the calliper parameter. For the choice of this parameter - see text.

The decompositions in panels I and II of Table 6 are similar but not identical. As expected, the number of matches is higher for calliper matching than in the exact matching. ${ }^{19}$ The differences between the components $\Delta_{f}, \Delta_{o}$ of these two decompositions do not show any clear pattern. The component $\Delta_{m}$ is systematically larger in calliper matching as compared to exact matching, while the component $\Delta_{x}$ is systematically lower (in all but one case). As a consequence, allowing even for small differences in the characteristics of matched men and women may significantly change the estimated components of the wage gap.

19 Notice that in general our exact matching is not the same as radius matching with calliper set to zero, since our exact matching requires all characteristics to be exactly the same, while radius matching with calliper zero requires the estimated propensity scores to be the same. 


\section{Conclusion}

In this paper, we have investigated gender wage differentials over the period of 1996-2003. We take into account that the supports of the distributions of characteristics can be different. This is an important issue since wage comparisons are relevant only when women are compared to "comparable" men. In our paper, we argue that gender differences in supports can be responsible for a substantial part of the wage gap. Indeed, the traditional social norms in Switzerland restrict the role of women on the labour market. Typically, men have priority on the labour market, while women stay at home and raise children. While this gender specialisation in different areas of life has been widely studied in the labour supply discussions, it has its own implications for the wage gap story. High selectivity of women in some jobs and economic sectors makes it difficult to estimate the counterfactual wages and thus to develop public policies aimed at promoting equality between women and men.

To our knowledge, the importance of recognizing the problem of gender differences in the supports has not yet been carefully addressed in any Swiss study about gender wage gap. The focus of the existing Swiss empirical studies is in disentangling the "explained" and "unexplained" components of the wage gap by using the traditional BLINDER-OAXACA (BO) decomposition. In our study, we use a matching method to decompose the wage gap. This method has been proposed by Nopo (2004) and leads to a decomposition into four components: the traditional "explained" and "unexplained" components (that are now defined over the common support only) and two additional components that account for wage differences for men and women in and out-of-the common support. This decomposition into four components sheds some light on the effect of applying parametric restrictions and on the bias which appears when the traditional BO decomposition is applied. For the Swiss data, this bias due to the violation of the common support appears to be large and commonly larger for earlier years of the study. Since the matching method is a data hungry method, the number of observations and the size of matched and unmatched samples might be not sufficient to perform a relevant statistical analysis on the wage gap using the SLFS data for the period 1991-1995. At the same time, the parametric restriction on the wage function has a much smaller effect, indicating that BO decomposition restricted to the common support, still remains a powerful tool to decompose the wage gap.

Our results show that over the period of study, the unexplained component remains relatively stable. In addition, differences between unmatched and matched women are stable over time. On the contrary, differences between matched and unmatched men narrow in time. This means that women have 
begun to penetrate traditionally men's areas. Indeed, the share of women with higher levels of education and occupying high qualified job positions increases over the period of observation. However, the distribution of female characteristics still differs from that of male characteristics even on the common support. This is reflected by the explained component of the wage gap which is steadily increasing since 1999. As a consequence, our results show that compared to the mid 1990s, differences in human capital nowadays matter more in explaining wage differentials than differences in the gender supports. Moreover, these latter differences account for a significant part of the wage gap.

The decomposition of the wage gap into four components has a useful interpretation in terms of policy implications aimed at reducing the male-female wage differentials. Currently, it is recommended to facilitate the access of women to a better education and to particular occupations. However, this policy is difficult to evaluate using the traditional BO decomposition, since it only yields one component of the wage gap which is due to the differences in characteristics, while the second "unexplained" component is the residual wage gap. On the contrary, the four component decomposition applied in this paper allows us to measure the effect of policies more precisely. For example, policies encouraging the combination between family and work would promote women to full-time positions. These women will be more likely to be matched and thus the differences between unmatched and matched women will decline (component $\Delta_{f}$ ). Similarly, policies targeted to reduce the barriers for the access to a better education will likely help matched women to reach male characteristics (this will affect the component $\Delta_{x}$ ). As a consequence, we can consider two different steps in order to obtain more wage equality between men and women. The first step consists in raising the human capital of those women who are currently unmatched to the level of the matched women. The second step is to remove dissimilarities between the distributions of men and women on the common support. Our analysis shows that these policies should have a larger effect on the total wage gap than struggles against legendary discrimination. 


\section{Appendix}

Appendix A.1

Education Level of the Prime Age Working Population, 1980-2000

\begin{tabular}{l|rrr|rrr}
\hline & \multicolumn{3}{|c|}{ Women } & \multicolumn{3}{c}{ Men } \\
& 1980 & 1990 & 2000 & 1980 & 1990 & 2000 \\
\hline obligatory schooling & 50.0 & 36.8 & 27.0 & 33.9 & 24.2 & 17.0 \\
apprenticeship training & 37.8 & 48.4 & 45.8 & 44.9 & 50.3 & 45.0 \\
general training & 6.0 & 6.1 & 11.2 & 2.9 & 2.6 & 6.2 \\
post apprenticeship training & 3.5 & 5.0 & 7.6 & 10.3 & 14.3 & 18.0 \\
university or technical college degree & 2.7 & 3.7 & 8.3 & 8.0 & 8.5 & 13.8 \\
\hline
\end{tabular}

Source: Census 1980, 1990 and 2000.

Occupation Degree in \% by Gender between 1970 and 2000

\begin{tabular}{l|cc|cc}
\hline \multirow{2}{*}{ Year } & \multicolumn{2}{|c|}{ Women } & \multicolumn{2}{c}{ Men } \\
\hline 1970 & Full-time & Part-time & Full-time & Part-time \\
1980 & 24.1 & 10.1 & 63.1 & 2.7 \\
1990 & 23.5 & 12.5 & 61.1 & 2.9 \\
2000 & 22.3 & 16.7 & 57.9 & 3.1 \\
\hline
\end{tabular}

Source: Census data.

Job Positions by Gender in 2001

\begin{tabular}{lcc}
\hline & Women & Men \\
\hline managers, executive employees & 3.2 & 7.5 \\
scientists and academicians & 12.0 & 19.8 \\
technicians & 24.1 & 17.3 \\
administrative personnel & 22.1 & 7.2 \\
personnel in services and retail trade & 20.3 & 6.8 \\
farmers & 3.5 & 5.5 \\
handworkers & 4.4 & 23.7 \\
operators & 1.8 & 7.4 \\
manual workers and assistants & 8.0 & 4.2 \\
\hline
\end{tabular}

Source: OFS report (2003) "Vers l'égalité?". 
Appendix A.2

Median Gross Monthly Wage by Gender and by Sector, 1994-2002

\begin{tabular}{l|ccc|ccc}
\hline & \multicolumn{3}{|c|}{ Private Sector } & \multicolumn{3}{c}{ Public Sector } \\
Year & Women & Men & Gap* & Women & Men & Gap \\
\hline 1994 & 3,927 & 5,153 & $23.8 \%$ & 5,376 & 6,181 & $13.0 \%$ \\
1996 & 4,086 & 5,300 & $22.9 \%$ & 5,523 & 6,250 & $11.6 \%$ \\
1998 & 4,253 & 5,417 & $21.5 \%$ & 5,568 & 6,193 & $10.1 \%$ \\
2000 & 4,358 & 5,551 & $21.5 \%$ & 5,672 & 6,316 & $10.2 \%$ \\
2002 & 4,586 & 5,796 & $20.9 \%$ & 5,695 & 6,377 & $10.7 \%$ \\
\hline
\end{tabular}

Source: OFS report (2003) "Vers l'égalité?".

Note: the wage is calculated on the basis of 4 and $1 / 3$ working weeks at 40 hours worked per week (this allows to convert part-time jobs to full-time equivalent jobs).

* gap in $\%$ of female wages

Median Wages by Industry Sector in 2002 (Private Sector Only)

\begin{tabular}{lcccc}
\hline & Women & Men & Gap* & Share* \\
\hline Sectors with the lowest wages & & & & \\
personnel services & 3,388 & 4,593 & $26.2 \%$ & $74.7 \%$ \\
restaurants, catering & 3,508 & 3,893 & $9.9 \%$ & $55.7 \%$ \\
textiles & 3,286 & 5,482 & $40.1 \%$ & $77.6 \%$ \\
\hline Sectors with the highest wages & & & & \\
real estate & 6,320 & 8,952 & $29.4 \%$ & $42.4 \%$ \\
research and development & 6,478 & 8,504 & $23.8 \%$ & $36.8 \%$ \\
banking, insurance & 6,067 & 8,808 & $31.1 \%$ & $36.8 \%$ \\
\hline Other economic sectors & & & & \\
construction & 5,012 & 5,361 & $6.5 \%$ & $9.9 \%$ \\
trade and repairs & 3,864 & 4,890 & $21.0 \%$ & $65.5 \%$ \\
\hline
\end{tabular}

Source: OFS report (2003) "Vers l'égalité?".

Note: the wage is calculated on the basis of 4 and $1 / 3$ working weeks at 40 hours worked per week (this allows to convert part-time jobs to full-time equivalent jobs).

* gap in $\%$ of female wages, and share of women 


\section{Appendix A.3}

\section{Explanatory Variables Used in the Analysis}

\begin{tabular}{|c|c|}
\hline Variables & Description \\
\hline \multicolumn{2}{|l|}{ Socio-demographics } \\
\hline Age & $\begin{array}{l}7 \text { categories: between } 15 \text { and } 24 \text {, between } 25 \text { and } 29 \text {, between } 30 \\
\text { and } 34 \text {, between } 35 \text { and } 39 \text {, between } 40 \text { and } 44 \text {, between } 45 \text { and } \\
49 \text { and older than } 49 \text {. }\end{array}$ \\
\hline Marital status & 4 categories: single, married, divorced and widowed. \\
\hline Level of education & $\begin{array}{l}3 \text { categories: primary (without education, primary school), sec- } \\
\text { ondary (elementary professional training, apprenticeship, full- } \\
\text { time professional school, general knowledge school, univer- } \\
\text { sity entrance qualification), tertiary (professional training with } \\
\text { master degree, technical and high professional school, university, } \\
\text { high school). }\end{array}$ \\
\hline Foreign citizenship & 2 categories: non Swiss and Swiss. \\
\hline Children & 2 categories: with and without children under 15 . \\
\hline \multicolumn{2}{|c|}{ Regional characteristics } \\
\hline Region of residence & $\begin{array}{l}2 \text { categories: Deutschschweiz (German part) and Westschweiz } \\
\text { (Latin part). }\end{array}$ \\
\hline \multicolumn{2}{|l|}{ Job characteristics } \\
\hline Firm size & $\begin{array}{l}3 \text { categories: less than } 50 \text { workers, between } 50 \text { and } 99 \text { workers } \\
\text { and more than } 100 \text { workers. }\end{array}$ \\
\hline Supervisory & Dummy if supervisory function. \\
\hline Occupation & $\begin{array}{l}8 \text { categories: managers, academicians, technicians, clerical work- } \\
\text { ers, services, handworkers, operators and assistants. }\end{array}$ \\
\hline Permanent & Dummy if permanent work contract. \\
\hline Public & Dummy if job in the public sector. \\
\hline Work experience & $\begin{array}{l}4 \text { categories: less than } 6 \text { months, between } 6 \text { and } 24 \text { months, } \\
\text { between } 2 \text { and } 5 \text { years and more than } 5 \text { years. }\end{array}$ \\
\hline
\end{tabular}

Notes: SLFS 1996-2003. 


\section{References}

Abadie, A., Drukker, D., Herr, J. and Imbens, G. (2003), „Implementing Matching Estimators for Average Treatment Effects in Stata", The Stata Journal, vol.4, pp. 290-311.

Abadie, A. and Imbens, G. W. (2004), "Large Sample Properties of Matching Estimators for Average Treatment Effects", NBER Working Paper, unpublished manuscript.

Altonji, J. and Blank, R. (1999), "Race and Gender in the Labor Market", in O. Ashenfelter and D. Card (eds), Handbook of Labor Economics, vol. 3, chap. 48, pp. 3143-3259.

Barsky, R., Bound, J., Charles, K. and Lupton, J. (2001), "Accounting for the Black-White Wealth Gap: A Nonparametric Approach", NBER Working Paper No. 8466, September 2001.

Blau, F. and KaHn, L. (1997), "Swimming Upstream: Trends in the Gender Wage Differential in the 1980s", Journal of Labor Economics, vol. 15, pp. 1-42.

Blau, F. and KaHn, L. (2000), "Gender Differences in Pay", Journal of Economic Perspectives, vol. 14, pp. 75-99.

Blinder, A. (1973), "Wage Discrimination: Reduced Form and Structural Estimates", Journal of Human Resources, vol. 8 (4), pp. 436-455.

Bonjour, D. (1997), Lohndiskriminierung in der Schweiz: Eine ökonometrische Untersuchung, Berner Beiträge zur Nationalökonomie, Bern-Stuttgart-Wien: Paul Haupt.

Bonjour, D. and Gerfin, M. (2001), "The Unequal Distribution of Unequal Pay - An Empirical Analysis of the Gender Wage Gap in Switzerland”, Empirical Economics, vol.26, pp.407-427.

Brüderl, J., Diekmann, A. and Engelhardt, H. (1993), „Einkommensunterschiede zwischen Frauen und Männern in der Schweiz“, Schweizerische Zeitschrift für Soziologie, vol. 19, pp. 573-588.

Diekmann, A. and Engelhardt, H. (1995), „Einkommensungleichheit zwischen Frauen und Männern. Eine ökonometrische Analyse der Schweizer Arbeitskräfteerhebung", Schweizerische Zeitschrift für Volkswirtschaft und Statistik, vol. 131, pp. 57-83.

FlüCkIger, Y. and Ramirez, J. (2000), «Analyse Comparative des Salaires entre les Hommes et les Femmes sur la Base de la LSE 1994 et 1996», Observatoire Universitaire de l'Emploi, University of Geneva.

Frölich, M. (2003), "Propensity Score Matching without Conditional Independence Assumption - with an Application to the Gender Wage Gap in the UK”, Discussion Paper, University of St. Gallen. 
Hahn, J. (1998), "On the Role of the Propensity Score in Efficient Semiparametric Estimation of Average Treatment Effects", Econometrica, vol.66, pp. 315-331.

Heckman, J., Ichimura, H. and Todd, P. (1998), "Matching as an Econometric Evaluation Estimator", Review of Economic Studies, vol. 65, pp. 261-294.

Heckman, J., Lalonde, R. and Smith, J. (1999), "The Economics and Econometrics of Active Labour Market Programs", in O. Ashenfelter and D. Card (eds), Handbook of Labour Economics, vol.3A, Amsterdam: North-Holland, pp. $1865-2097$.

Henneberger, F. and Sousa-Poza, A. (1998), "Estimating Wage Functions and Wage Discrimination Using Data from the 1995 Swiss Labour Force Survey: A Double-Selectivity Approach", International Journal of Manpower, vol. 19, pp. 486-506.

Henneberger, F. and Sousa-Poza, A. (1999), „Geschlechtsspezifische Lohndiskriminierung. Neueste Evidenz von den Mikrodaten aus der Schweizerischen Arbeitskräfteerhebung", Schweizerische Zeitschrift für Soziologie, vol. 25, pp. 259-279.

KugLeR, P. (1988), „Lohndiskriminierung in der Schweiz. Evidenz von Mikrodaten", Schweizerische Zeitschrift für Volkswirtschaft und Statistik, vol. 124, pp. 23-47.

Lalive, R. and Stutzer, A. (2004), "Approval of Equal Rights and Gender Differences in Well-Being", IZA Discussion Paper No. 1202, July 2004.

Lechner, M. (2001), "A Note on the Common Support Problem in Applied Evaluation Studies", Discussion Paper 2001-01, University of St. Gallen.

Lechner, M., Miquel, R. and Wunsch, C. (2004), "Long-Run Effects of Public Sector Sponsored Training in West Germany", Discussion Paper 2004-06, University of St. Gallen.

Leuven, E. and Sianesi, B. (2003), "PSMATCH2: Stata Module to Perform Full Mahalanobis and Propensity Score Matching, Common Support Graphing, and Covariate Imbalance Testing".

Mulligan, C. and Rubinstein, Y. (2005), "Selection, Investment and Women's Relative Wages since 1975”, NBER Working Paper No. 11159.

Nopo, H. (2004), "Matching as a Tool to decompose Wage Gaps", IZA Discussion Paper No. 981, January 2004.

OAXACA, R. (1973), "Male-Female Differentials in Urban Labor Markets", International Economic Review, vol. 14, pp. 693-709.

OFS (2003), «Vers l'égalité? La situation des femmes et des homes en Suisse», troisième rapport statistique, Neuchâtel. 
OFS (2005), «Avancée et stagnation dans la problématique de l'égalité entre hommes et femmes de 1970 à 2000", Neuchâtel.

Olivetti, C. and Petrongolo, B. (2006), "Unequal Pay or Unequal Employment? A Cross-Country Analysis of Gender Gaps", IZA Discussion Paper No. 1941.

Rosenbaum, P. and Rubin, D. (1983), "The Central Role of the Propensity Score in Observational Studies for Causal Effects", Biometrika, vol.70, pp. 41-55.

Sousa-Poza, A. (2002), "Labor Market Segmentation and the Gender Wage Gap: An Industry-Level Analysis for Switzerland", Cabiers Economiques de Bruxelles, vol. 45, pp. 91-118.

Sousa-Poza, A. (2003), "The Gender Wage Gap and Occupation Segregation in Switzerland”, 1991-2001, Discussion Paper No. 89, University of St. Gallen.

WaLdFogel, J. (1998), “Understanding the 'Family Gap' in Pay for Women with Children", Journal of Economic Perspectives, vol. 12, pp. 157-170.

Weichselbaumer, D. and Winter-Ebmer, R. (2005), "A Meta-Analysis on the International. Gender Wage Gap", Journal of Economic Surveys, vol. 19 (3), pp. 479-511.

\section{SUMMARY}

In this paper, we investigate the gender wage differentials for Switzerland. Using micro data from the Swiss Labour Force Survey, we apply a matching method to decompose the wage gap in Switzerland. This nonparametric technique accounts for wage differences that can be due to differences in the supports. We can interpret these differences as a form of "discrimination" which is reflected in wages because women face "barriers" in accessing certain characteristics that men achieve. As a consequence, accounting for these differences in gender supports may be useful in terms of policy implications in promoting more equality between men and women. 